\title{
Gaming disorder among students of Tabriz University of Medical Sciences: The frequency and related factors
}

\author{
Maryam Vahidi ${ }^{1}$, Vahid Zamanzadeh ${ }^{2}$, Saeed Musavi ${ }^{3}$, Fariborz Roshangar ${ }^{2}$, Raheleh Janani ${ }^{2} * \mathbb{D}$ \\ Received: 11 May 2020 \\ Published: 2 Aug 2021
}

\begin{abstract}
Background: Gaming disorder has been identified as a health problem. Disorders in emerging adulthood might negatively affect individuals' attitude toward the world, their communication with others, and formation of their personal identity. Thus, the present study was performed to identify the frequency of gaming disorder and its related factors among students of Tabriz University of Medical Sciences.

Methods: A total of 813 undergraduate students of Tabriz University of Medical Sciences participated in this descriptive correlational study in 2018. All students filled the personal-social information form and Social Readjustment Rating Scale, and gamers filled gaming behaviors form and Internet gaming disorder-20 test (IGD). Data were analyzed using descriptive statistics and Pearson correlation coefficient, $\mathrm{t}$ - test, ANOVA, chi-square, and multiple linear regression.

Results: A total of $394(48.5 \%)$ students were currently playing games. The mean of IGD scores among the gamers was 45.47 \pm 13.93 , and $17(4.3 \%)$ of them were recognized as having gaming disorder. The frequency of the disorder among all students was 17 (2.1\%). Being male, playing online games, and having access to all 3 gaming devices (computer, smart phone, and tablet) were recognized as determining factors of gaming disorder.

Conclusion: This study revealed that almost half of the university students were playing video and or on line games; however, a low percentage of the gamers had addictive gaming behaviors. The results indicated the necessity of applying modifications to individuals' gaming methods as well as implementing the individual and family-centered interventions to prevent and manage gaming disorder.
\end{abstract}

Keywords: Video Games, Internet, Behavior, Addictive, University students

Conflicts of Interest: None declared

Funding: This work was supported by the Research Center of Psychiatry and Behavioral Science of Tabriz University of Medical Sciences.

*This work has been published under CC BY-NC-SA 1.0 license.

Copyright $($ Iran University of Medical Sciences

Cite this article as: Vahidi M, Zamanzadeh V, Musavi S, Roshangar F, Janani R. Gaming disorder among students of Tabriz University of Medical Sciences: The frequency and related factors. Med J Islam Repub Iran. 2021 (2 Aug);35:98. https://doi.org/10.47176/nnjiri.35.98

\section{Introduction}

In recent years, it has been admitted that addiction is not restricted to the behaviors induced from uncontrolled usage of substance, yet there are some so-called harmless behaviors that might be addictive in distinct occasions and

Corresponding author: Raheleh Janani, jananir@tbzmed.ac.ir

1. Research Center of Psychiatry and Behavioral Sciences, Tabriz University of Medical Sciences, Tabriz, Iran

2. Faculty of Nursing and Midwifery, Tabriz University of Medical Sciences, Tabriz, Iran

3. Faculty of Health, Tabriz University of Medical Sciences, Tabriz, Iran violate individuals' life seriously. In the Diagnostic and Statistical Manual of Mental Disorders, $5^{\text {th }}$ edition (DSM5), a new diagnostic category has been added called substance-related and addictive disorders. In this category,

$\uparrow$ What is "already known" in this topic:

Use of digital devices and the Internet is prevalent among university students. One of the motivations for students to use them is to provide entertainment such as games. Gaming disorder has been identified as a health problem.

$\rightarrow$ What this article adds:

This study revealed almost half of the university students were playing video and /or on line games; however, a low percentage of the gamers had addictive gaming behaviors. Moreover, being male, playing online games, and accessing all 3 gaming devices (computer, smart phone, and tablet) were determining factors of this disorder. 
there is also a section on disorders not related to substance. Although this section includes only gambling disorders, in section III, internet gaming disorder (IGD) has been added (1). Section III includes the disorders that require more studies to be considered as an independent disorder (2).

Moreover, gaming disorder has been included in the WHO International Classification of Diseases $11^{\text {th }}$ revision. In this edition, gaming disorder has been defined as a constant or frequent gaming behavior (digital or video games) that encompass both online and offline games. This disorder is displayed as (1) disturbed control over gaming (such as starting the game, frequency, severity, duration, stopping, and background), (2) too much prioritizing the game as it results in exclusion of other life interests and daily activities, and (3) continuing or intensifying the gaming behavior despite unfavorable and negative consequences. To be diagnosed, the disorder is required to be severe enough to cause a notable disturbance concerning personal, family, social, educational, occupational, or other important performance matters. In addition, to diagnose the disorder, gaming behaviors, and other features need to be apparent for 12 months. However, the duration could be shorter in case all diagnostic requirements are met and severe symptoms exist (3).

The results of the study by Wang in school students showed that one-sixth of them had video or internet gaming dependency (4). Other studies have reported the prevalence of Internet gaming disorder to be noticeably different between $1.3 \%$ and $17.7 \%(5-10)$.

The results of some other studies show that gaming disorders are associated with sleeping disturbance, school drop-out, low academic performance (11), depression symptoms (12), aggressive behaviors (13), attention disorders (14), low self-esteem, low life satisfaction (15), anxiety $(16,17)$, imbalanced family $(4)$, suicide thoughts and plans, increased daily life problems, tension and neuroticism personality traits, high extroversion, and low conscientiousness (18).

The target population in most of the studies was the individuals younger than 18 years. However, in some studies, it has been stated that the stereotype of a male teenager as a classic gaming addict is no longer dealt with, as most of the gamers are young men (2). Arnett has considered the age between 18 to 29 years as emerging adulthood. Instability and numerous changes are the features of this period, which include changes in academic status and living place (leaving parental home to study or get married) and entering the business world. Disorders in this period might have a negative effect on individuals' attitude toward the world, their relationships, and forming their personal identity $(19,20)$. The most undergraduate students are in this age range. Use of digital devices and the Internet is prevalent among this age group.

A study in Iran showed that $98 \%$ of students are Internet users and $21 \%$ of them are problematic users (21). One of the motivations for students to use the Internet is to provide entertainment, such as online games. According to a qualitative study, students reported problems with their health and education due to the use of online games and some of them had bad relationships with friends and family (22).

Considering that gaming disorder has been identified as a health problem, it is necessary to enhance our knowledge about its prevalence and its related factors in different groups, as APA has suggested that more investigative studies should be done on this issue. On the other hand, in Iran, gaming disordler and its effects has not drawn the sociologists' attention yet, which results from the novelty of the issue. Therefore, awareness of the students' gaming behaviors and its related factors could help health policymakers to for plan appropriate educational or preventive programs.

\section{Methods}

This was a descriptive correlational study performed in 2018 in Tabriz University of Medical Sciences. The study population consisted of undergraduate students of nursing and midwifery, health, nutrition and food sciences, paramedicine, rehabilitation, and management and medical informatics faculties. Inclusion criteria were as follows: being an undergraduate student; having access to smartphone, tablet, or computer; and willingness to participate in the study.

The sample size was calculated as 994 using the results of the study by Potenz et al (23), in which amount of error was $0.01, \mathrm{P}=.053$ and $\mathrm{N}=2018$. Type 1 error was supposed to be .05 . The proportional random sampling method was used.

$$
\begin{aligned}
& \varepsilon=z \sqrt{\frac{p(1-p)}{n}} \sqrt{\frac{N-n}{N-1}} \\
& n_{0}=\frac{z^{2} p(1-p)}{\varepsilon^{2}} \\
& n=\frac{n_{0} N}{n_{0}+(N-1)}
\end{aligned}
$$

To collect the data, personal-social information form, gaming behaviors form, and IGD test questionnaire were used. Personal-social questionnaire included gender, age, marital status, field of study (major), semester, residency (dorm or others), number of close friends, perceived stress level, and perceived loneliness, parents' educational level, economical status of the family, students' grade point average (GPA) in previous semester (the score between 0 20), students' academic self-assessment, and relationship quality with classmates and professors. Perceived stress level, perceived loneliness, and relationship quality with classmates and professors were assessed by 4 questions, including "How much stress have you experienced in the past year," "How much loneliness have you experienced in the past year," "How is your relationship with your classmates," and "How is your relationship with your professors," respectively. The rate of stress was measured using the Social Readjustment Rating Scale. Gaming behaviors form included type of game (online, offline, indi- 
vidual, group) and gaming device.

The IGD test includes 20 items that reflects 9 IGD criteria in DSM-5. Additionally, this instrument includes the elements of theoretical framework of addiction model (salience, mood modification, tolerance, withdrawal symptoms, conflict, and relapse). IGD-20 test investigates both online and offline gaming behaviors during last 12 months. The items of IGD were rated in the 5-point Likert scale including completely disagree, disagree, neutral, agree, completely disagree, with the lowest and the highest points of 1 and 5, respectively. The score range of IGD items is between 20 and 100 . The cutting point of the instrument is 71 , out of which the higher points are considered as the cases having diagnostic criteria for Internet gaming disorder (23). After obtaining the permission for using the instrument, the original version was translated from English into Persian. To achieve content validity, the questionnaire was reviewed by 10 faculty members of Tabriz University of Medical Sciences and their corrective opinions were applied. To identify the instrument's internal consistency, the questionnaire was completed by 20 students and Cronbach alpha was achieved as 0.91 .

Stress Scale (Social Readjustment Rating Scale) was developed by Holmes and Rihe in 1967. The Scale is a list including 43 stressful life events such as spouse's death, divorce, fire at workplace, sexual problems, et cetera. For each event, a score has been assigned considering its severity. Stressful life events have been defined as the occurrences causing readjustment changes in an individual's normal performance. The sum of points is considered as the index of an individual' s experienced stress in a distinct period of time (24). In this study, the most recent year was considered as the distinct period of time. In Iran, the reliability of the scale was evaluated by Manouchehri et al among university students and it was determined by Cronbach alpha coefficient as 0.75 (25).

The study was approved by the regional ethics committee in Tabriz University of Medical Sciences (IR.TBZMED.REC.1395.771). First, the total number of students of each major was obtained. Afterward, samples were proportionately and randlomly selected from among majors based on the calculated sample size. Participants were selected through preparing the list of students' names and assigning a number to each one at random using a random number generator. Then, the researcher referred to the classes or the clinical training units at the end of class time to not interfere with the student learning process. After obtaining permission from the professor, explaining the study purpose, and obtaining informed consent from the eligible students, students were requested to complete the questioners. They were asked to complete IGD-20 if they were currently playing games. Participants were assured about their voluntary nature of their participation and confidentiality of their information.

Data were analyzed using SPSS version13 (SPSS Corp). First, the normality of the data distribution was approved using the Kolmogorov-Smirnov test. Afterward, data were analyzed using descriptive statistics (mean, standard deviation, frequency, and percentage) and inferential statistics (Pearson correlation coefficient, t-test, ANOVA, chisquare, and multiple linear regression) considering .05 as significant.

\section{Results}

A total of 813 undergraduate students of Tabriz University of Medical Sciences participated in this study. Of them, 170 participants were excluded from the study due to their unwillingness to complete the questionnaire. In addition, 11 incomplete questionnaires were excluded. The mean age of participants was 21.48 (2.51) and the mean of their GPA was 16.79 (1.60). The majority of the participants were girls $(n=530[65.3 \%])$, single $(n=697$ [85.7\%]), and stayed in dorms $(n=470$ [57.8\%]). The number of students from the faculties of nursing and midwifery, paramedicine, health, nutrition and food sciences, rehabilitation and management, and medical informatics was $367(45.1 \%), 163(20.0 \%), 72(8.9 \%), 33(4.0 \%)$, $109(13.4 \%)$, and $69(8.5 \%)$, respectively. Table 1 demonstrates the personal-social information among gamers and nongamers.

\begin{tabular}{|c|c|c|c|}
\hline Variable & & Gamers $\mathrm{f}(\%)(\mathrm{N}=394)$ & Non gamers $\mathrm{f}(\%) \quad(\mathrm{N}=416)$ \\
\hline \multirow[t]{2}{*}{ Gender } & Male & $200(38)$ & $327(62)$ \\
\hline & Female & $194(68.8)$ & $88(31.2)$ \\
\hline \multirow[t]{3}{*}{ Marital status } & Single & $351(50.5)$ & $344(49.5)$ \\
\hline & Married & $37(34.9)$ & $69(65.1)$ \\
\hline & Divorced & $2(100)$ & $0(0)$ \\
\hline \multirow[t]{2}{*}{ Residence status } & Living with family & $228(48.7)$ & $240(51.3)$ \\
\hline & Living in dormitory & $163(48.7)$ & $172(51.3)$ \\
\hline \multirow[t]{3}{*}{ Economic status of the family } & Income equal with living expenses & $213(48.6)$ & $225(51.4)$ \\
\hline & Income greater than living expenses & $118(48.8)$ & $125(51.2)$ \\
\hline & Income less than living expenses & $47(49.5)$ & $48(50.5)$ \\
\hline \multirow[t]{3}{*}{ Number of close friends } & $\leq 2$ & $140(44.3)$ & $176(55.7)$ \\
\hline & $3-6$ & $184(49.2)$ & $190(50.8)$ \\
\hline & $\geq 7$ & $70(58.8)$ & $49(41.2)$ \\
\hline \multirow[t]{3}{*}{ Perceived stress level } & High & $244(51.3)$ & $232(48.7)$ \\
\hline & Low & $130(46.6)$ & $149(53.4)$ \\
\hline & Without feeling of stress & $19(35.2)$ & $35(64.8)$ \\
\hline \multirow[t]{3}{*}{ Perceived loneliness } & High & $168(53)$ & $149(47)$ \\
\hline & Low & $188(48.3)$ & $201(51.7)$ \\
\hline & Without feeling of loneliness & $38(36.9)$ & $65(63.1)$ \\
\hline
\end{tabular}




\begin{tabular}{|c|c|c|c|}
\hline \multicolumn{4}{|l|}{ Table 1. Ctd } \\
\hline Variable & & Gamers $\mathrm{f}(\%)(\mathrm{N}=394)$ & Non gamers $\mathrm{f}(\%) \quad(\mathrm{N}=416)$ \\
\hline \multirow[t]{5}{*}{ Perceived harmony in family } & Very good & $87(44.4)$ & $109(55.6)$ \\
\hline & Good & $148(47.3)$ & $165(52.7)$ \\
\hline & Normal & $121(52.2)$ & $111(47.8)$ \\
\hline & Bad & $30(58.8)$ & $21(41.2)$ \\
\hline & Very bad & $6(46.3)$ & $7(53.8)$ \\
\hline \multirow[t]{5}{*}{ Students' academic self-assessment } & Very good & $20(38.2)$ & $51(71.8)$ \\
\hline & Good & $143(52.4)$ & $130(47.6)$ \\
\hline & Normal & $155(49.8)$ & $156(50.2)$ \\
\hline & Bad & $52(47.3)$ & $58(52.7)$ \\
\hline & Very bad & $19(51.4)$ & $19(51.4)$ \\
\hline \multirow{5}{*}{ Relationship with classmates } & Very good & $65(44.5)$ & $81(55.5)$ \\
\hline & Good & $198(48.9)$ & $207(51.1)$ \\
\hline & Normal & $111(49.3)$ & $114(50.7)$ \\
\hline & Bad & $14(60.9)$ & $9(39.1)$ \\
\hline & Very bad & $6(54.4)$ & $5(45.5)$ \\
\hline \multirow[t]{5}{*}{ Relationship with professors } & Very good & $60(43.8)$ & $77(56.2)$ \\
\hline & Good & $185(48.3)$ & $198(51.7)$ \\
\hline & Normal & $128(51)$ & $123(49)$ \\
\hline & Bad & $14(66.7)$ & $7(33.3)$ \\
\hline & Very bad & $9(60)$ & $6(40)$ \\
\hline \multirow[t]{6}{*}{ Gaming device } & computer & $22(5.6)$ & $30(7.3)$ \\
\hline & Tablet & $3(0.8)$ & $4(1.0)$ \\
\hline & Smartphone & $134(34.1)$ & $172(41.7)$ \\
\hline & Smartphone/ computer & $162(41.2)$ & $144(35.0)$ \\
\hline & Smartphone/Tablet & $11(2.8)$ & $16(3.9$ \\
\hline & All devices & $61(15.5)$ & $46(11.2)$ \\
\hline GPA of previous semester & & $16.56 \pm 1.71$ & $17.03 \pm 1.45$ \\
\hline Age & & $21.39 \pm 2.24$ & $21.54 \pm 2.66$ \\
\hline Score of Holmes and Rahe Stress Scale & & $101.16 \pm 78.55$ & $82.76 \pm 62.12$ \\
\hline
\end{tabular}

A total of 394 students (48.5\%) of 813 participants were playing games. Among them, 27.8\% played online games, $58.6 \%$ played offline games, and $13.6 \%$ played both. Moreover, 60.9\% played individual games, 23.7\% played group games, and $15.4 \%$ played both.

The mean of IGD score among gamers was $45.47 \pm 13.93$. Considering the cut point of the instrument, from among all 394 users, $4.3 \%(n=17$ participants $)$ were recognized as having IGD disorder and the frequency of the disorder in the study population was $2.1 \%$.

The results of the data analysis showed a statistically significant correlation between the IGD score with social readjustment rating scale score $(\mathrm{P}=0.006 ; \mathrm{R}=0.160)$ and GPA ( $\mathrm{P}=0.016, \mathrm{R}=-0.136)$. However, there was no statistically significant correlation between age and IGD score $(P=0.315 ; R=0.052)$. Table 2 shows the comparison of IGD score with personal-social information and gaming behaviors of the students.

Table 2. Comparing the IGD Score With Demographic Features and Gaming Behaviors of Students ${ }^{\mathrm{a}}$

\begin{tabular}{|c|c|c|c|c|c|c|c|}
\hline \multicolumn{2}{|l|}{ Variables } & \multirow{2}{*}{$\frac{\text { Mean } \pm \text { SD }}{50.20 \pm 14.43}$} & \multirow{2}{*}{$\frac{\text { P Value }}{<0.001}$} & \multicolumn{2}{|c|}{ Variables } & \multirow{3}{*}{$\frac{\text { Mean } \pm \text { SD }}{50.02 \pm 14.01}$} & \multirow{2}{*}{$\frac{\mathrm{p}}{<0.001}$} \\
\hline Gender & Male & & & Type of the & Online & & \\
\hline & Female & $41.51 \pm 12.05$ & & game & Offline & & \\
\hline \multirow[t]{3}{*}{ Marital status } & Single & $45.73 \pm 13.98$ & 0.338 & Number of & $\leq 2$ & $47.33 \pm 15.18$ & 0.261 \\
\hline & Married & $45.13 \pm 11.48$ & & close friends & $3-6$ & $44.97 \pm 13.85$ & \\
\hline & Divorced & $31.50 \pm 0.70$ & & & $\geq 7$ & $44.78 \pm 11.33$ & \\
\hline \multirow{3}{*}{$\begin{array}{l}\text { Residence } \\
\text { status }\end{array}$} & Living with family & $46.16 \pm 13.65$ & 0.473 & Type of the & Individual & $43.03 \pm 12.73$ & 0.003 \\
\hline & Living in dormitory & $45.13 \pm 14.46$ & & game & group & $48.31 \pm 13.05$ & \\
\hline & No formal education & $37.00 \pm 0.00$ & 0.339 & Relationship & Very good & $44.73 \pm 15.32$ & $<0.001$ \\
\hline \multirow{4}{*}{$\begin{array}{l}\text { Father educa- } \\
\text { tion }\end{array}$} & Elementary & $45.64 \pm 11.75$ & & with class- & Good & $43.12 \pm 11.74$ & \\
\hline & Secondary & $47.27 \pm 13.91$ & & mates & Normal & $49.54 \pm 14.4$ & \\
\hline & High school & $47.58 \pm 13.70$ & & & Bad & $51.71 \pm 18.21$ & \\
\hline & University & $44.32 \pm 14.81$ & & & Very bad & $60.00 \pm 21.34$ & \\
\hline \multirow{5}{*}{$\begin{array}{l}\text { Mather edu- } \\
\text { cation }\end{array}$} & No formal education & $37.00 \pm 0.00$ & 0.670 & Relationship & Very good & $42.85 \pm 14.02$ & $<0.001$ \\
\hline & Elementary & $46.43 \pm 13.29$ & & with profes- & Good & $43.40 \pm 12.01$ & \\
\hline & Secondary & $46.66 \pm 14.88$ & & sors & Normal & $48.39 \pm 14.05$ & \\
\hline & High school & $46.46 \pm 14.00$ & & & $\mathrm{Bad}$ & $58.07 \pm 17.26$ & \\
\hline & University & $44.24 \pm 14.02$ & & & Very bad & $65.83 \pm 20.82$ & \\
\hline \multirow{5}{*}{$\begin{array}{l}\text { Economic } \\
\text { status of the } \\
\text { family }\end{array}$} & Income equal with liv- & $46.01 \pm 13.91$ & 0.677 & Students' & Very good & $41.70 \pm 12.55$ & $<0.001$ \\
\hline & ing expenses & & & academic self- & Good & $41.68 \pm 10.75$ & \\
\hline & Income greater than & $45.33 \pm 14.60$ & & assessment & Normal & $48.01 \pm 14.51$ & \\
\hline & living expenses & $47.48 \pm 13.76$ & & & $\mathrm{Bad}$ & $48.51 \pm 16.28$ & \\
\hline & $\begin{array}{l}\text { Income less than living } \\
\text { expenses }\end{array}$ & & & & Very bad & $55.21 \pm 17.17$ & \\
\hline
\end{tabular}

${ }^{a}$ IGD, Internet gaming disorder. 


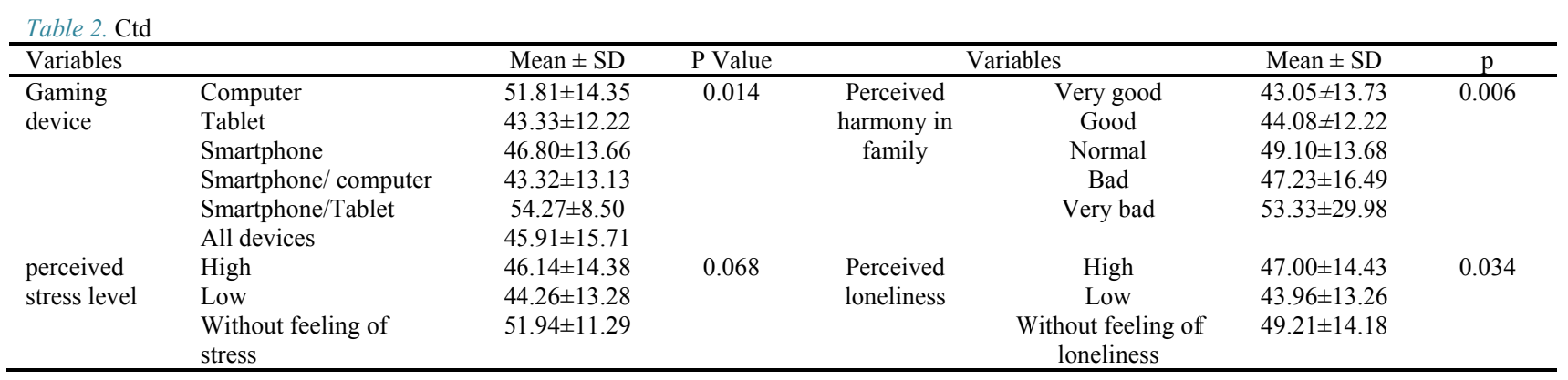

Table 3. Predictors of the IGD Scores in Multiple Linear Regression ${ }^{\text {a }}$

\begin{tabular}{lcccc}
\hline Variables & B & SE & B & T \\
\hline Constant & 31.345 & 10.455 & 2.998 & 0.003 \\
Being male & 7.585 & 1.918 & .276 & 3.955 \\
Gaming online & 4.999 & 2.018 & .155 & 2.477 \\
Having all gaming devices & 13.040 & 5.832 & .148 & 0.001 \\
\hline${ }^{a}$ IGD, Internet gaming disor & & 0.014 & 2.236 \\
\hline
\end{tabular}

The results of regression test showed that being male, playing online games, and accessing all 3 gaming devices (computer, smart phone, and tablet) were determining factors of the IGD score (Table 3).

\section{Discussion}

Results of this study showed that half of the students were playing on line and video games. Therefore, such gaming was a relatively common and prevalent phenomenon among students. However, a small percentage of gamers had gaming disorder behaviors, as $4.3 \%$ were classified as having addictive gaming behaviors. Consequently, it seems that playing games was a harmless entertainment for most of the participants. Some studies reported positive effects of playing game, such as a boost in their visual short-term memory and an improvement in the quality of their friendship (13). Similarly, previous studies reported the $1.3 \%$ to $17.7 \%$ of its prevalence. In a study in Turkey, the prevalence of the disorder was reported to be $1.3 \%$ after 455 individuals aged 10 to 29 years were investigated using a short form of the instrument (5). In Spain, a study conducted in 1074 individuals aged 12 to 58 revealed the prevalence of the disorder as $2.6 \%$ using the same instrument (6). In the study by Wang in school students of Hong Kong, it was reported that $15.6 \%$ of the participants were addicted to the internet or video games (7). In a study in Germany, the prevalence of the disorder was $5.7 \%$ among individuals aged 12 to 29 years (8). In another study conducted in Slovenia on teenager students with the age mean of 13.5 years, the disorder prevalence was reported to be $2.5 \%$ to $4.7 \%$ (9). In another study on 1251 participants aged 13 to 40 years, using the 9-item instrument, the prevalence of the disorder was $17.7 \%$ (10). The difference between the percentages could be related to diversity of the study population, instrument, and culture.

The results of the present study showed that being male was one of the determining factors of gaming disorder. This result was in agreement with previous studies $(4,26$, 27). It could be because of different usages of online activities by girls and boys. Boys are usually interested in Internet gaming; however, girls utilize the Internet to use social media (28).

The results indicated that gaming behaviors, including playing online games and accessing all 3 gaming devices (computer, lap top, and smart phone) were determining factors of gaming disorder. Similarly, in the study by Wang, playing online games was identified as one of the factors associated with gaming disorder (4). It seems that individuals play games to evade the actual life problems. Online games interest such people greatly since they can regularly be updated and can provide communication opportunities; as a result, they are encouraged to stay in the virtual world. As the results of the univariable tests, family and personal problems, such as high level of perceived loneliness, low level of perceived balance in the family, low level of perceived academic performance, and high scores of Rahe Stress Scale were associated with the higher scores of gaming disorder. The literature shows that individuals turn to emotion- or problem-focused coping mechanisms when encountering stressful events and upsetting occasions. In problem-focused mechanism, the individual tries to solve the problem. However, in emotion-focused mechanism, the aim is not solving the problem but doing some activities to decrease the emotions such as anxiety, sorrow, rage, fear, and guilt. Playing games and doing recreational activities are types of application of the recent mechanism (29). This result shows the necessity of individual and family- centered interventions in order to prevent and treatment gaming disorder.

Moreover, accessing various devices for playing the games causes the individuals to be able to play the game at any time in various ways at home, at work, at study place, and outdoors, and it increases their preoccupation with virtual world and takes them away from an actual communication. The results of the study by Starvropoulos alike indicated that vast social withdrawal was associated with internet gaming disorder (30). It seems that in addition to individual and family psychological interventions for alleviating the individual and family conflicts, modifications should to be applied to individuals' gaming habits to prevent them from social life withdrawal. Providing educational courses for students concerning the games, gaming methods, and the side effects could be helpful in 
managing the use of games. Installing the games on the computer instead of the smartphone may be helpful in limiting the gaming time only to home.

In this study, the questionnaires were self-reported, which might have created the possibility of bias or giving incorrect information. Therefore, it is suggested that further studies use clinical diagnostic interviews to confirm the disorder cases. In addition, this study population were the students of Tabriz University of Medical Sciences, which limits the generalization of the findings to other populations. Previous studies have shown that culture influences the individuals' gaming behaviors. Consequently, it is recommended that more studies be conducted in different cultures to identify the factors related to gaming disorder.

\section{Conclusion}

The results of the present study revealed that almost half of the university students were playing video and internet games; however, a low percentage of the gamers had addictive gaming behaviors. Moreover, being male, playing online games, and accessing all 3 gaming devices (computer, smart phone, and tablet) were determining factors of the IGD score. The study results indicated the necessity of applying modifications on individuals' gaming habits as well as implementing individual and family-centered interventions in order to prevent and manage gaming disorder. Providing educational courses for students about games, their side effects, and playing methods could help manage the use of the games.

\section{Acknowledegment}

Hereby, authors highly appreciate the participation of the students of Tabriz University of Medical Sciences in this study.

\section{Conflict of Interests}

The authors declare that they have no competing interests.

\section{References}

1. American Psychiatric Association. Diagnostic and statistical manual of mental disorders. 5 ed. Washington 2013.

2. Pontes HM, Griffiths MD. Assessment of internet gaming disorder in clinical research: Past and present perspectives. Clin Res Regul Aff. 2014;31(2-4):35-48.

3. International Classification of Diseases for Mortality and Morbidity Statistics. ICD-11: World health organization; 2011 [11:[Available from: https://icd.who.int/dev11/1-m/en\#/http $\% 3 a \% 2 f \% 2$ fid.who.int $\% 2$ ficd\%2fentity\%2f1448597234.

4. Wang CW, Chan CL, Mak KK, Ho SY, Wong PW, Ho RT. Prevalence and correlates of video and internet gaming addiction among Hong Kong adolescents: a pilot study. Sci World J. 2014;2014:874648.

5. Arıcak OT, Dinç M, Yay M, Griffiths MD. Adapting the short form of the internet gaming disorder scale into Turkish: Validity and reliability. Addicta. 2018.

6. Fuster H, Carbonell X, Pontes HM, Griffiths MD. Spanish validation of the Internet Gaming Disorder-20 (IGD-20) Test. Comput Hum Behav. 2016;56:215-24.

7. Wang HR, Cho H, Kim DJ. Prevalence and correlates of comorbid depression in a nonclinical online sample with DSM-5 internet gaming disorder. J Affect Disord. 2018;226:1-5.

8. Wartberg L, Kriston L, Thomasius R. The Prevalence and
Psychosocial Correlates of Internet Gaming Disorder. Dtsch Arztebl Int. 2017;114(25):419-24.

9. Macur M, Pontes HM, Griffiths MD. OR-65: Prevalence rates of Internet Gaming Disorder among Slovenian youth: Findings from a nationally representative study. J Behav Addict. 2016;5(S1):27-9.

10. Subramaniam M, Chua BY, Abdin E, Pang S, Satghare P, Vaingankar JA. Prevalence and correlates of Internet gaming problem among Internet users: results from an Internet survey. Ann Acad Med Singapore. 2016;45(5):174-83.

11. Rehbein F, Kliem S, Baier D, Miossle T, Petry NM. Prevalence of Internet gaming disorder in German adolescents: diagnostic contribution of the nine DSM- 5 criteria in a state-wide representative sample. Addiction (Abingdon, England). 2015;110(5):842-51.

12. Ryu H, Lee JY, Choi A, Park S, Kim DJ, Choi JS. The Relationship between Impulsivity and Internet Gaming Disorder in Young Adults: Mediating Effects of Interpersonal Relationships and Depression. Int J Environ Res Public Health. 2018;15(3)).

13. Muller KW, Janikian M, Dreier M, Wolfling K, Beutel ME, Tzavara $\mathrm{C}$, et al. Regular gaming behavior and internet gaming disorder in European adolescents: results from a cross-national representative survey of prevalence, predictors, and psychopathological correlates. Eur Child Adolesc Psychiatry. 2015;24(5):565-74.

14. Gonzalez-Bueso V, Santamaria JJ, Fernandez D, Merino L, Montero E, Jimenez-Murcia S, et al. Internet Gaming Disorder in Adolescents: Personality, Psychopathology and Evaluation of a Psychological Intervention Combined With Parent Psychoeducation. Front Psychol. 2018;9:787.

15. Ko CH, Yen JY, Chen CC, Chen SH, Yen CF. Gender differences and related factors affecting online gaming addiction among Taiwanese adolescents. J Nerv Ment Dis. 2005;193(4):273-7.

16. Torres-Rodriguez A, Griffiths MD, Carbonell X, Oberst U. Internet gaming disorder in adolescence: Psychological characteristics of a clinical sample. J Behav Addict. 2018;7(3):707-18.

17. Wu Y, Sescousse G, Yu H, Clark L, Li H. Cognitive distortions and gambling near-misses in Internet Gaming Disorder: A preliminary study. PLoS One. 2018;13(1):e0191110.

18. Ohm HS, Cho MJ, Hong JP, Hahm BJ, Chung IW, Ahn JH, et al. The Differences of Suicidal Belhavior, Stress, Internet Gaming Disorder-Related Symptoms and Prersonality Traits between Internet Game Overusers and General Users. Psychiatry Investig. 2014;53(6):402-9.

19. Arnett JJ. Emerging adulthood. A theory of development from the late teens through the twenties. Am Psychol. 2000;55(5):469-80.

20. Arnett JJ, Žukauskienè R, Sugimura K. The new life stage of emerging adulthood at ages 18-2.9 years: implications for mental health. Lancet Psychiatry. 2014;1(7): :569-76.

21. Mazhari S. The Prevalence of Problematic Internet Use and the Related Factors in Medical Students, Kerman, Iran. Addict Health. 2012;4(3-4):87-94.

22. Wang L, S. Z. Online Game Addiction Among University Students 2011 [Available from: https:/www.divaportal.org/smash/get/diva2:602320/FULLTEXT01.pdf.

23. Pontes HM, Kiraly O, Demetrovics Z, Griffiths MD. The conceptualisation and measurement of DSM-5 Internet Gaming Disorder: The development of the IGD-20 Test. PLoS One. 2014;9(10):e110137.

24. Dohrenwend BP. Inventorying stressful life events as risk factors for psychopathology: Toward resolution of the problem of intracategory variability. Psychol Bull. 2006;132(3):477-95.

25. Manoochehri A, Behroozi N, Shehni Yeylag M, Maktabi G. Testing the Model of the Relationship Bettween Positive Perfectionism and Negative Life Events with Coping Styles and Psychological WellBeing: The Mediating Role of Psychological Capital. Sci J Manag Syst. 2019;15(60):419-34.

26. Wartberg L, Kriston L, Thomasius R. The Prevalence and Psychosocial Correlates of Internet Gaming Disorder. Dtsch Arztebl Int. 2017;114(25):419-24.

27. Borges G, Orozco R, Benjet C, Martínez Martínez KI, Contreras EV, Jiménez Pérez AL, et al. DSM-5 Internet gaming disorder among a sample of Mexican first-year college students. J Behav Addict. 2019;8(4):714-24.

28. Lin C, Yu S. Adolescent internet usage in Taiwan: exploring gender differences. Adolescence. 2008;43(170): 317-31.

29. Asadi noghabi A, Omidi SH, HajiAgajani S. Psychiatric Nursing Mental Health Fundamentals. 5 ed. Tehran: Boshra Publications; 
2010

30. Stavropoulos V, Anderson EE, Beard C, Latifi MQ, Kuss D, Griffiths M. A preliminary cross-cultural study of Hikikomori and Internet Gaming Disorder: The moderating effects of game-playing time and living with parents. Addict Behav Rep. 2019;9. 